\title{
The Reconstruction of Pink Esthetics Through Gingival Depigmentation- A Case Series
}

\section{Prebha Manickam*, Shivanand Aspalli, Shirin A Mulla and Parimala Djeapragassam}

Penang International Dental College, Butterworth, Penang, Malaysia

*Corresponding Author: Prebha Manickam, Penang International Dental College, Butterworth, Penang, Malaysia.

DOI: 10.31080/ASDS.2020.04.0786
Received: January 23, 2020

Published: February 13, 2020

(C) All rights are reserved by Prebha

Manickam., et al.

\begin{abstract}
Health and appearance of gingiva is an essential part of esthetic smile. The importance of achieving harmony between zeniths of free gingival margin and drape of upper lip is often less stressed in the global community. Gingival hyperpigmentation poses itself as an esthetic problem with patients complaining about their black gums. Esthetic gingival depigmentation procedures can be performed in such patients with excellent results. Limited awareness, less motivation and higher cost makes it a difficult treatment for the common man. Among the various techniques available for depigmentation, few have shown better results in terms of cost, patient satisfaction and the recurrence rates. This case series presents a split mouth de-epithelization procedure using scalpel and electrocautery and gives an insight on these treatment modalities, thus making it a beneficial approach for desired individuals.
\end{abstract}

Keywords: Gingiva; Melanin; Pigmentation; Depigmentation; Electrosurgery

\section{Key Messages}

Gingival depigmentation is a plastic surgical procedure within the confines of dentistry wherein the gingival pigmentation is removed or reduced by various techniques. There is an array of techniques for depigmentation using deepitheliazation, electrosurgery, cryosurgery, chemical agents and laser.

\section{Introduction}

Importance of pink (gingival) esthetics in a smile cannot be underestimated in enhancement of beauty, confidence and personality of a person. Advances in esthetic dentistry strive to merge function and beauty of this smile with the values and the individual needs of patients. Is this esthetic treatment made available to desired individuals?

Limited awareness, less accessibility and the exorbitant rates makes this dental treatment a question. The proper channelization of the dental workforce and motivation on cost and result effective treatments can help in catering to the desired individual's esthetic needs. Thereby, clinicians can make over smile by not only correcting the color, shape and position of teeth but also by achieving gin- gival esthetics with simple and economical yet effective techniques.

The color of healthy gingiva is variable, ranging from a pale pink to a deep bluish purple hue with the normal being the coral pink [1]. Pigmentation of the oral mucosa is clinically manifested as multifocal or diffuse melanin pigmentation ranging from a variety of clinical entities, ranging from physiologic changes (e.g., racial pigmentation) to manifestations of systemic illnesses (e.g., Addison's disease) and malignant neoplasms (e.g., melanoma and Kaposi's sarcoma) [2].

Studies by Perlmutter [1] have concluded that the size and degree of melanization of the melanin granules is directly proportional to the degree of pigmentation. In dark-skinned and black individuals, an increased melanin production has long been known to be the result of genetically determined hyperactivity of melanocytes. Although clinically melanin pigmentation of the gingiva does not present any medical problems and is completely benign, it can be of esthetic concern [3]. Gingival depigmentation is a plastic surgical procedure within the confines of dentistry wherein the gingival pigmentation is removed or reduced by various techniques. There 
is an array of techniques for depigmentation using deepitheliazation, electrosurgery, cryosurgery, chemical agents and laser.

This article emphasizes the importance of depigmentation procedures through a case series using a split mouth de-epithelization procedure with scalpel and electrocautery and compares the clinical parameters and effectiveness using melanin pigmentation index (Takeshi., et al.) [4] (Table 1) and healing index (Landry., et al.) [5] (Table 2).

\begin{tabular}{|l|c|}
\hline Score & Degree of Melanin Depigmentation \\
\hline 0 & No pigmentation \\
\hline 1 & $\begin{array}{c}\text { Solitary unit (s) of pigmentation in papillary gingiva } \\
\text { without extension between neighboring solitary units }\end{array}$ \\
\hline 2 & $\begin{array}{c}\text { Formation of continuous ribbon extending from neigh- } \\
\text { boring solitary units }\end{array}$ \\
\hline
\end{tabular}

Table 1: Melanin pigmentation index (takashi et al) [10].

\begin{tabular}{|c|c|c|c|c|c|c|}
\hline Score & Category & Tissue color & $\begin{array}{c}\text { Response to } \\
\text { palpation-bleeding }\end{array}$ & $\begin{array}{l}\text { Granulation } \\
\text { tissue }\end{array}$ & Incision margin & Suppuration \\
\hline 1 & Very poor & $>50 \%$ of gingiva red & Present & Present & $\begin{array}{l}\text { Not epithelialized, withloss } \\
\text { of epithelium beyond } \\
\text { incision margin }\end{array}$ & Present \\
\hline 2 & Poor & $? 50 \%$ of gingiva red & Present & Present & $\begin{array}{l}\text { Not epithelialized with } \\
\text { connective tissue exposed }\end{array}$ & Absent \\
\hline 3 & Good & $\begin{array}{l}? 25 \% \text { and }<50 \% \text { of } \\
\text { gingiva red }\end{array}$ & Absent & Absent & $\begin{array}{c}\text { No connective tissue } \\
\text { exposed }\end{array}$ & Absent \\
\hline 4 & $\begin{array}{l}\text { Very } \\
\text { good }\end{array}$ & $<25 \%$ of gingiva red & Absent & Absent & $\begin{array}{c}\text { No connective tissue } \\
\text { exposed }\end{array}$ & Absent \\
\hline 5 & Excellent & $\begin{array}{l}\text { All tissues pink with } \\
\text { or without physiologi- } \\
\text { cal pigmentation }\end{array}$ & Absent & Absent & $\begin{array}{l}\text { No connective tissue } \\
\text { exposed }\end{array}$ & Absent \\
\hline
\end{tabular}

Table 2: Healing index by landry RG turnbull RS howley T [6].

\section{Case history}

Three patients with gingival hyperpigmentation, visiting the department of periodontics at A.M.E's Dental college, Raichur, Karnataka., were given an insight on the advances in esthetic dentistry and the procedure of depigmentation. Clinical examination revealed pronounced bilateral melanin pigmentation associated with a healthy periodontium. The patients were in good general health and there were no contraindications for the surgeries. The area of gingival hyperpigmentation (area of interest) was marked by two vertical and horizontal lines for demarcating it from the uninvolved area (Figure 1a). All pigmented areas were graded from two according to the melanin pigmentation index.

\section{Scalpel de-epithelization}

On the left side of the maxillary arch, No. 15 surgical grade blade on a bard parker handle was used. (Figure 1b) The procedure was performed through scraping epithelium with underlying pigmented layer (in attached gingival area). A uniform layer of the epithelium was scrapped from the underlying connective tissue to prevent nicks, cuts and underlying alveolar bone exposure. Special care was taken in the free gingival margin area as improper epithelial excision might lead to gingival recession in that area. The raw surface was thoroughly irrigated with saline and povidone iodine (1:1) to remove any loose tissue tags.

\section{Electrosurgery method}

Electrosurgery unit was used to deepithelize the hyperpigmented areas on the contralateral side of the arch. (Figure 1c) Ablation of the pigmented tissues was done using loop electrodes under standard protective measures. It involves the passage of radiowaves at the frequency of 1.5 to 4.5. MHz. Remnants of ablated tissues were removed with the sterile gauze damped in saline solution. This was repeated until the pigmented areas of epithelium were ablated. Light brushing strokes were used and the tip was kept moving all the time. Prolonged or repeated application of electrode to the tissues was avoided as it induces heat accumulation and causes undesired tissue destruction.

On completion of surgical procedure, a periodontal dressing was placed over the surgical area and oral hygiene instructions were 
given to the patients. (Figure 1d and 1e) The patients were prescribed non-steroidal anti-inflammatory drugs and chlorhexidine mouthwash. One week following the surgery, the patients were reviewed and the periodontal dressing was removed (Figure 1f,1g).

\section{Results}

At the $1^{\text {st }}$ week, the gingiva was pale and tender with mild inflammation at the canine-premolar regions in the areas done by electrosurgery (figure $1 \mathrm{~g}$ ) whereas healing index showed a score of 3 for areas done by scalpel. (Figure 1f). Healing was uneventful thereafter. Although electrosurgery has advantages of minimal bleeding and a cleaner work field, it requires more expertise and caution. The graphs showed a better healing index for the deepithelization done by surgical blade than electocautery at the first week. (Graph 1 and 2) The results with the conventional scalpel technique and electrosurgery were comparatively similar.

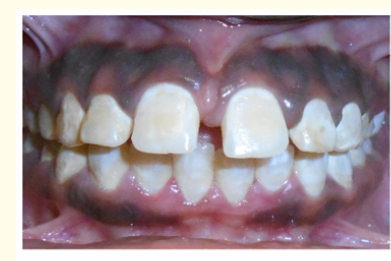

a. Pre-operative view

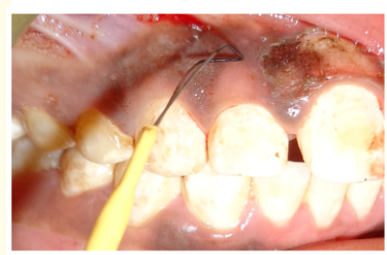

c. Electrocautery ablation

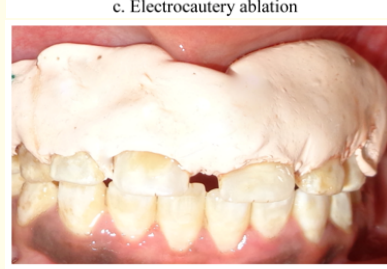

e. Periodontal dressing given

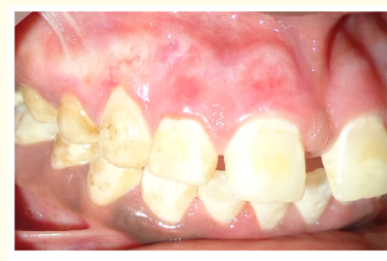

g. Quadrant done by electrocautery -one week later

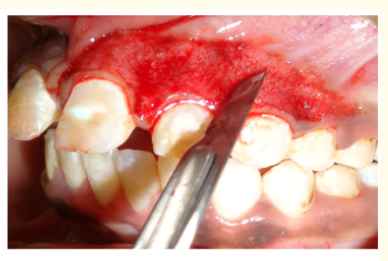

b.Scalpel deepithelisation

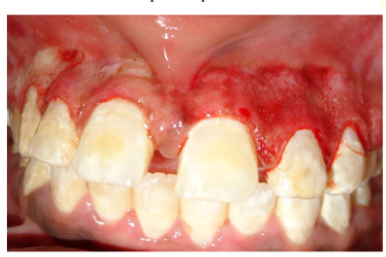

d. Immediate post operative view

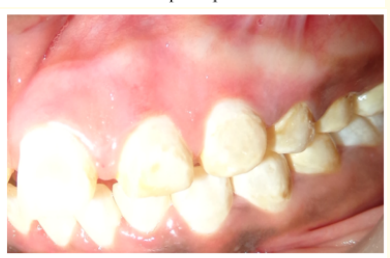

f.. Quadrant done by scalpel - one week later

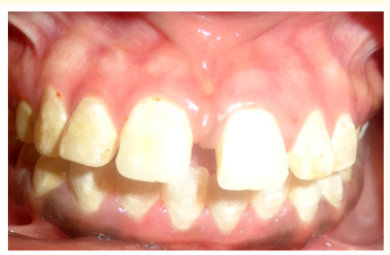

h. Post operative view - at third month
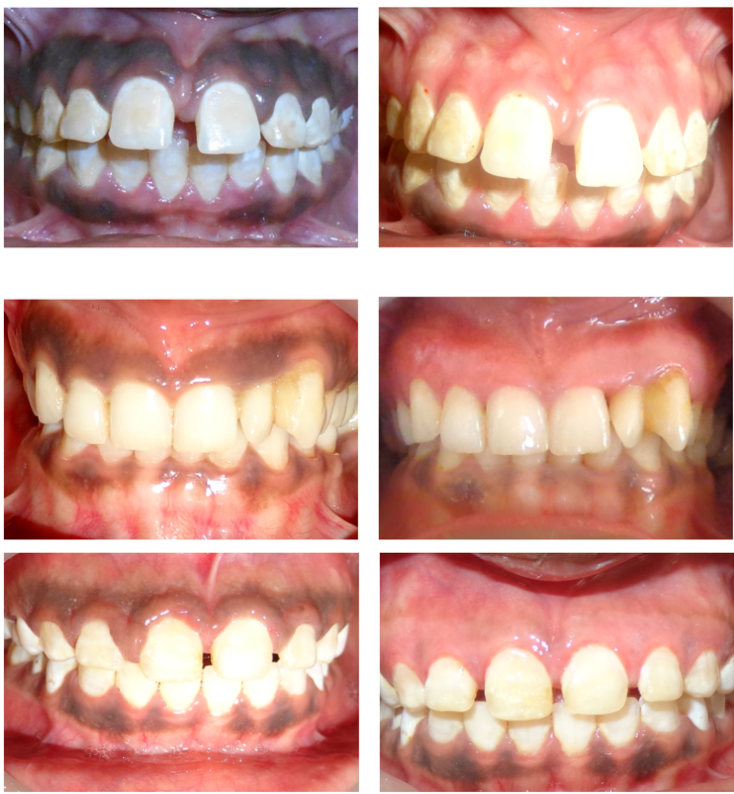

Figure 2: Pre-operative and post-operative.

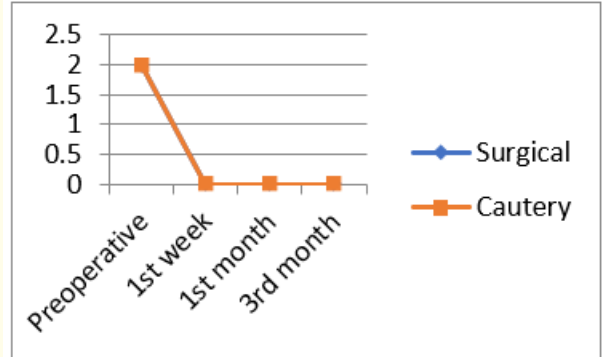

Graph 1: Depigmentation index.

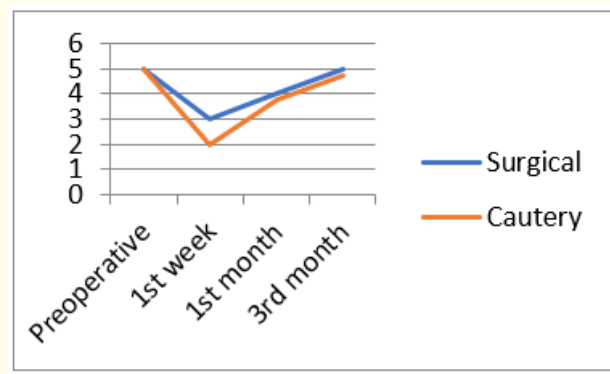

Graph 2: Healing index.

Figure 1: Depigmentation by deepithelisation using scalpel and electrocautery. 


\section{Discussion}

Evidence based results of a systemic review found cryosurgery, electrosurgery and laser exhibits optimal predictability for depigmentation of the gingiva among all procedures examined.6 On the other hand, scalpel de-epithelization was easy and techniquefriendly, economical and resulted in good patient satisfaction with healing period faster than the other techniques [7].

Wound healing is influenced by revascularization rate, preservation and reconstruction of microvasculature. The initial response after depigmentation is the formation of protective surface clot which is then replaced by granulation tissue. Capillaries derived from blood vessels of the periodontal ligament migrate into the granulation tissue and within 2 weeks, they connect with gingival vessels. Vascularity returns to normal in about 2 - 3 weeks. After 5-14 days surface epithelialization is generally complete, but complete epithelial repair takes about 1 month [8]. The procedure using the surgical blade essentially involves surgical scrapping of the gingival epithelium allowing the denuded connective tissue to heal by secondary intention. In case of electrosurgery, the heat produced is solely the result of the resistance offered by the tissue to the passage of the current.

There was a delayed wound healing in the areas done by electrosurgery at $1^{\text {st }}$ week. Studies done by Mannivannan., et al. [9] comparing the gingival blood flow have shown comparatively decreased blood perfusion in the areas done by electrosurgery when compared to that of scalpel at the $7^{\text {th }}$ day. This could be the reason for the delay in healing. Depigmentation by scalpel technique is relatively simple and effective, and most economical of all the other techniques available. Studies by Almas., et al. [7] and Kathriya., et al. [10] suggested that the healing period for scalpel wound is faster than the other techniques. This is in accordance with the present study.

The next concern is the recurrence of pigmentation. Though the techniques showed no signs of repigmentation, pigment recurrence has been documented to occur, following the surgical procedure, within 24 days to 8 years long period. Spontaneous repigmentation has been shown to occur and the mechanism suggested is that the epidermal melanin unit, rather than the melanocyte alone, serves as the focal point for melanin metabolism within epidermis. This unit proliferates and migrates from the adjacent normal areas into the depigmented areas. Further, the degradation of melanosomes by lysosomal enzymes may yield small molecules which pass back by way of the keratinocytes or intercellular spaces to influence melanocyte performance through biological feedback [11]. The factors affecting rate and length of time required for recurrence of pigmentation should be studied.

\section{Conclusion}

Pink esthetics can be made in reach to desired individuals with the help of simple techniques. This mainly depends on the dentistpatient interaction to motivate them and heighten their awareness on the cost and result effective treatment modalities. Scalpel deepithelization technique is one of the first and still popular techniques employed for correction of gingival hyperpigmentation. It is relatively simple and effective, and most economical of all the other techniques available. This technique is highly recommended in the Indian subcontinent considering equipment constraints and patient affordability. This case series found minimum discomfort and maximum patient satisfaction when done with scalpel technique, with no signs of recurrence after a 3 month follow up period. During the follow-up periods, both the techniques produced comparable results with regard to healing and no recurrence. The cases are being tracked to notice signs of recurrence, as repigmentation may occur post depigmentation. There is still scant literature regarding the control on repigmentation after its treatment. Therefore, research should focus on finding its permanent solution, till then, repeated depigmentation and regular follow-up is the only available option currently.

\section{Bibliography}

1. Perlmutter $\mathrm{S}$ and Tal H. "Repigmentation of the gingiva following surgical injury". Journal of Periodontology 57 (1986): 48-50.

2. Dummett CO. "Clinical observation on pigment variations in healthy oral tissues in the Negro". Journal of Dental Research 24 (1945): 7-13.

3. Dummett CO., et al. "The relationship of facial skin complexion to oral mucosa pigmentation and tooth color". Journal of Prosthetic Dentistry 43 (1980): 392-396.

4. Takashi H., et al. "Association of melanin pigmentation in the gingiva of children with parents who smoke". Pediatrics 116 (2005): e186-e190.

5. Landry RG., et al. "Effectiveness of benzydamyneHCl in the treatment of periodontal post-surgical patients". Research in Clinic Forums10 (1988): 105-118.

Citation: Prebha Manickam., et al. "The Reconstruction of Pink Esthetics Through Gingival Depigmentation- A Case Series". Acta Scientific Dental Sciences 4.3 (2020): 42-46. 
6. Lin YH., et al. "Systematic review of treatment modalities for gingival depigmentation: a random-effects poisson regression analysis". Journal of Esthetic and Restorative Dentistry 26.3 (2014): 162-178.

7. Almas K and Sadig W. "Surgical treatment of melanin-pigmented gingiva; an esthetic approach". Indian Journal of Dental Research 13.2 (2002): 70-73.

8. Watanabe Y and Suzuki S. "An experimental study in capillary vascularization in the periodontal tissue following gingivectomy or flap operation". Journal of Dental Research 42 (1963): 758.

9. Manivannan N., et al. "Scalpel versus electrosurgery: Comparison of gingival perfusion status using ultrasound Doppler flowmetry". Journal of Pharmacy and Bioallied Sciences 5.2 (2013): S154-S59.

10. Kathariya R and Pradeep AR. "Split mouth de-epithelization techniques for gingival depigmentation: A case series and review of literature". Journal of Indian Society of Periodontology 15 (2011): 161-168.

11. Quevedo WC. "Epidermal Melanin Units: Melanocyte-Keratinocyte Interactions”. American Zoologist 12.1 (1972): 35-41.

\section{Assets from publication with us}

- Prompt Acknowledgement after receiving the article

- Thorough Double blinded peer review

- Rapid Publication

- Issue of Publication Certificate

- High visibility of your Published work

Website: www.actascientific.com/

Submit Article: www.actascientific.com/submission.php

Email us: editor@actascientific.com

Contact us: +919182824667

Citation: Prebha Manickam., et al. "The Reconstruction of Pink Esthetics Through Gingival Depigmentation- A Case Series”. Acta Scientific Dental Sciences 4.3 (2020): 42-46. 